\title{
4D strain analysis within non-infarcted myocardium of patients with ischemic cardiomyopathy: potential marker for the prediction of adverse cardiac events
}

\author{
Alessandro Satriano ${ }^{1,2^{*}}$, Nowell M Fine ${ }^{2}$, Kate Fenwick ${ }^{4}$, Dexter D Waters ${ }^{5}$, Yoko Mikami ${ }^{1,2}$, Haris Vaid ${ }^{6}$, \\ Derek V Exner ${ }^{3}$, Carmen P Lydell ${ }^{1,7}$, Andrew G Howarth ${ }^{1,2}$, James A White ${ }^{1,2}$, Bobak Heydari ${ }^{1,2}$
}

From 19th Annual SCMR Scientific Sessions

Los Angeles, CA, USA. 27-30 January 2016

\section{Background}

Adverse left ventricular remodeling following myocardial infarction (MI) remains one of the strongest prognostic indicators of adverse cardiac events. Increased wall stress and biomechanical strain within non-infarcted myocardium contribute to myocyte hypertrophy, fibrosis, and late adverse remodeling. This study aimed to demonstrate the feasibility of performing 4D strain analysis within noninfarcted myocardial segments through spatial registration to late gadolinium enhancement (LGE) imaging by cardiac magnetic resonance imaging (CMR) in ischemic cardiomyopathy (ICM) patients.

\section{Methods}

Ninety-one patients from the ongoing prospective REFINE-ICD clinical trial underwent 1.5 Tesla CMR imaging (Avanto, Siemens, Germany) with multi-planar cine SSFP and LGE. Commercial software (cvi42, Circle Cardiovascular Inc.) was used to analyze LV volumes and perform segmental LGE analysis using a $\geq 3 \mathrm{SD}$ signal threshold. Segmental 4D strain analysis was incrementally performed using GIUSEPPE, an in-house software, with analysis restricted to those segments without LGE. In addition, 40 normal controls underwent identical 4D strain analysis. Inclusion criteria for the REFINE-ICD study includes adults with a history of prior myocardial infarction (3-15 months) and left ventricular ejection fraction (LVEF) between 36-50\%.

\section{Results}

Mean age of the ICM patients was $60.8 \pm 9.7$ years with mean LVEF of $41.7 \pm 7.1 \%$. The mean infarct size (percent of total myocardium) was $40.5 \pm 12.7 \%$. The findings of segmental 4D strain analysis are shown in Table 1 and Figure 1. Mean segmental principal, circumferential, and radial strain were significantly lower within non-infarcted myocardial segments compared to the myocardium of healthy controls. Linear regression analyses demonstrated a strong association between mean segmental principal strain and both LVEF and left-ventricular end-systolic volume. There was no association identified between observed strain values and total infarct size.

Table 1 Mean strain in normal patients and in remote segments of patients with ischemic cardiomyopathy.

\begin{tabular}{cccc}
\hline Strain Variables & Normals & $\begin{array}{c}\text { ICM (remote } \\
\text { segments) }\end{array}$ & $\begin{array}{c}\text { p- } \\
\text { value }\end{array}$ \\
\hline Maximum Principal & $74.76 \pm$ & $55.4 \pm 18.9$ & $<0.0001$ \\
Strain & 20.9 & & \\
Minimum Principal & $-20.04 \pm$ & $-18.04 \pm 3.2$ & $<0.001$ \\
Strain & 2.8 & & \\
Circumferential Strain & $-15.01 \pm$ & $-11.59 \pm 2.0$ & $<0.0001$ \\
& 2.1 & & \\
Radial Strain & $56.32 \pm$ & $39.35 \pm 16.6$ & $<0.0001$ \\
& 16.5 & & 0.08 \\
Longitudinal Strain & $-12.54 \pm$ & $-11.7 \pm 2.6$ & \\
& 2.3 & &
\end{tabular}

'Stephenson Cardiac Imaging Centre, Calgary, AB, Canada

Full list of author information is available at the end of the article 

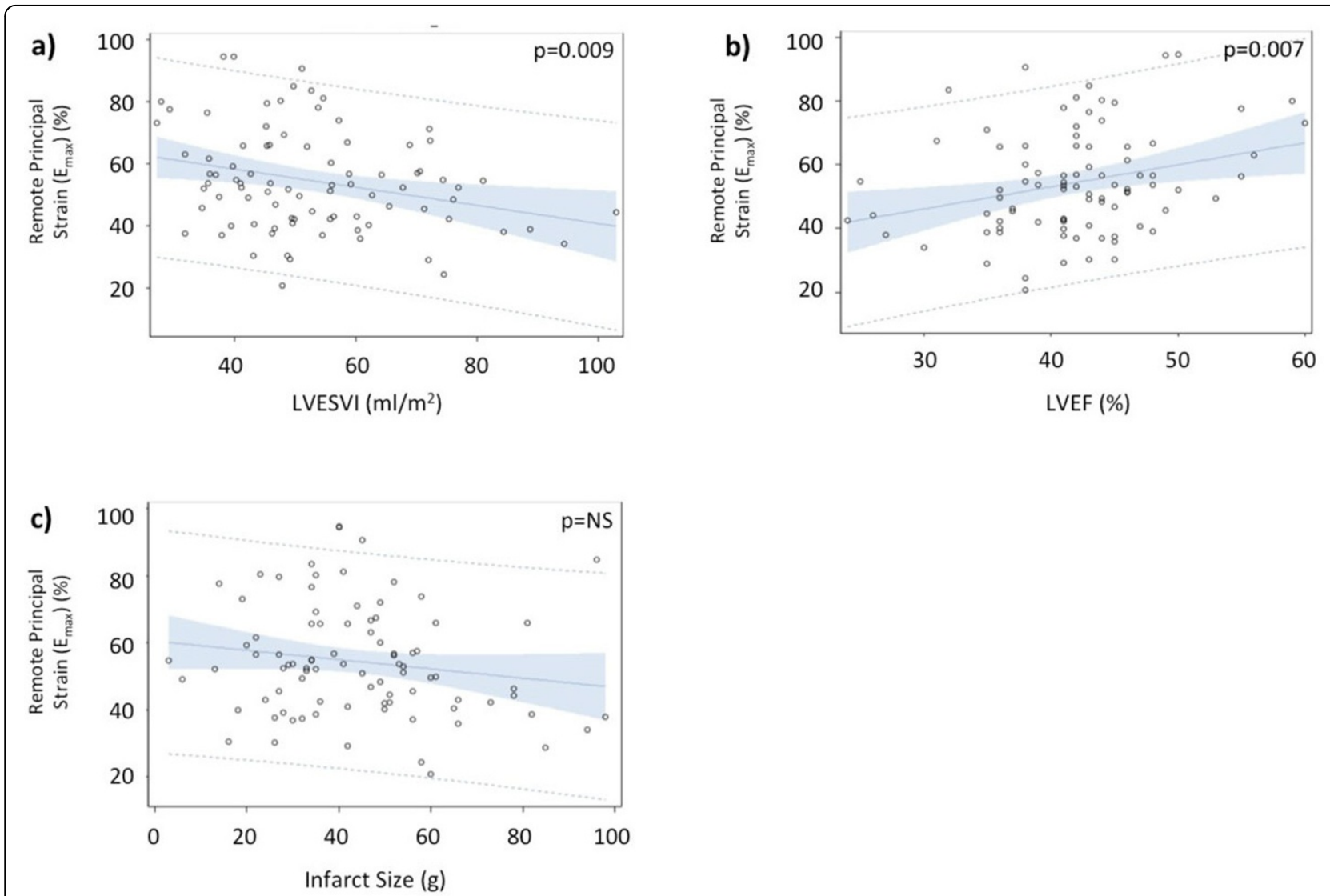

Figure 1 Linear regression of Remote Maximum Principal Strain $\left(E_{\max }\right)$ vs. LVESVI (a), LVEF (b) and Infarct Size (c) in patients affected by Ischemic Cardiomyopathy.

\section{Conclusions}

This study shows the feasibility of spatially matched 4D strain and LGE analysis to evaluate regional biomechanical strain of non-infarcted myocardial tissue in patients with an ischemic cardiomyopathy. Our results confirm impaired contractility relative to normal controls, independent of infarct size, and highlights the potential of remote tissue strain analysis to be evaluated as a prognostic marker for adverse cardiac events within this population.

\section{Authors' details}

${ }^{1}$ Stephenson Cardiac Imaging Centre, Calgary, AB, Canada. ${ }^{2}$ Division of Cardiology, School of Medicine, University of Calgary, Calgary, AB, Canada. ${ }^{3}$ Libin Cardiovascular Institute of Alberta, Calgary, AB, Canada. ${ }^{4}$ Queen's University, Kingston, AB, Canada. ${ }^{5}$ McGill University, Montréal, QC, Canada. ${ }^{6}$ University of Calgary, Calgary, AB, Canada. ${ }^{7}$ Department of Diagnostic Imaging, University of Calgary, Calgary, $A B$, Canada.

Published: 27 January 2016

doi:10.1186/1532-429X-18-S1-P233

Cite this article as: Satriano et al: 4D strain analysis within non-infarcted myocardium of patients with ischemic cardiomyopathy: potential marker for the prediction of adverse cardiac events. Journal of Cardiovascular Magnetic Resonance 2016 18(Suppl 1):P233.
Submit your next manuscript to BioMed Central and take full advantage of:

- Convenient online submission

- Thorough peer review

- No space constraints or color figure charges

- Immediate publication on acceptance

- Inclusion in PubMed, CAS, Scopus and Google Scholar

- Research which is freely available for redistribution 